\title{
A UTILIZAÇÃO DE RODAS DE CONVERSA COMO ESTRATÉGIA DE COMPARTILHAMENTO DE PRÁTICAS PEDAGÓGICAS NOS DIFERENTES CURSOS DA ESCOLA POLITÉCNICA
}

DOI: 10.37702/2175-957X.COBENGE.2021.3569

Claudio Luis Crescente Frankenberg - claudio@pucrs.br

Pontifícia Universidade Católica do Rio Grande do Sul

Rua São Manoel 1568

90620-110 - Porto Alegre - RS

Denize Regina Carniel - denize.carniel@pucrs.br

Pontifícia Universidade Católica do Rio Grande do Sul

Rua Casemiro de Abreu 771

90420-001 - Porto Alegre - RS

Lucia Giraffa - giraffa@pucrs.br

Pontifícia Universidade Católica do Rio Grande do Sul

Avenida Ipiranga 6681 predio 32

90610-900 - Porto Alegre - RS

Thaísa Jacintho Müller - thaisamuller@gmail.com

PUCRS

Rua Dona Augusta 333

90850-130 - Porto Alegre - RS

Resumo: Este artigo apresenta as ações formativas organizadas no formato de rodas de conversa com objetivo de criar espaços de interlocução que permitisse o compartilhamento de práticas pedagógicas organizadas/criadas ou adaptadas pelos professores dos diferentes cursos da escola Politécnica de uma Universidade comunitária, onde estão alocados os cursos de Engenharia. Esta estratégia veio complementar os tradicionais espaços formativos organizados no formato de palestras e curso online ofertado pelo Núcleo de Inovação Pedagógica (NIP) da escola. A experiência resultou na criação de uma rede de interesses e partilhas, por parte dos professores, auxiliando na reflexão acerca da necessidade de inovação no fazer pedagógico tendo como base o contexto atual da cibercultura. As rodas iniciaram antes do contexto pandêmico e, durante estes três semestres 


\section{COBENGE de Educação em Engenharia

de ofertas remotas, criou-se mais um espaço que permitiu aos docentes se encontrarem para partilhar descobertas, dúvidas, angústias e criarem soluções remixadas para utilizarem de forma adaptada para suas disciplinas.

Palavras-chave: Rodas de Conversa. Ensino Síncrono Emergencial Remoto. Estratégias Pedagógicas. Formação Docente. 


\section{A UTILIZAÇÃO DE RODAS DE CONVERSA COMO ESTRATÉGIA DE COMPARTILHAMENTO DE PRÁTICAS PEDAGÓGICAS NOS DIFERENTES CURSOS DA ESCOLA POLITÉCNICA}

\section{INTRODUÇÃO}

Este artigo tem como objetivo apresentar reflexões relacionadas à formação docente continuada em serviço, com finalidade de criar espaços de interlocução que permitissem o compartilhamento de práticas pedagógicas organizadas/criadas ou adaptadas pelos professores dos diferentes cursos da Escola Politécnica de uma Universidade Comunitária, onde estão alocados os cursos de Engenharia, Informática, Arquitetura e Urbanismo, Ciências Aeronáuticas, Matemática, Física e Química.

Com a reorganização estrutural e administrativa da Universidade em Escolas, em 2018, foram necessários novos itens organizacionais para apoiar a gestão pedagógica da Pró-Reitoria de Graduação (PROGRAD). A fim de capilarizar as ações de inovação pedagogia à luz do PPI (Projeto Pedagógico Institucional) alicerçado em abordagem construtivista e o educar pela pesquisa, foram constituídos, em cada Escola, os Núcleos de Inovação Pedagógica (NIPs). O detalhamento sobre esta alteração institucional e a criação dos NIPs pode ser observado em Frankenberg et al (2019), que traz em detalhes as atribuições e ações do NIP da Escola Politécnica.

Com a intenção de engajar os professores em atividades que promovam espaço para trocas e potencial construção de inovações em suas práticas, criou-se um programa de formação continuada em serviço.

É importante destacar que a prática pedagógica contempla significados e interpretações que os docentes atribuem a suas ações. Essas ações, por sua vez, potencialmente consolidam uma inovação no sentindo de provocar mudanças nas ações desenvolvidas que desencadeiam processos de ensino e de aprendizagem significativos para todos os envolvidos. Buscou-se em Sacristán (1999) o respaldo teórico para justificar a escolha das rodas de conversa num contexto onde os docentes, na sua maioria não possuem formação didático-pedagógica específica para trabalhar as questões relacionadas ao fazer docente e participar de cursos relacionados a processos formativos que envolvem aspectos pedagógicos. Felizmente, observa-se uma mudança neste comportamento em função da emergência imposta pelo contexto pandêmico, o qual impeliu os docentes a reformularem e ressignificarem seu fazer docente em face dos desafios de transporem as atividades do presencial para o virtual.

Para Sacristán (1999, p. 74): "a prática é, então, sinal cultural de saber fazer composto de formas de saber como, ainda que ligado também a crenças, a motivos e a valores coletivos".

No que concerne à inovação de práticas, é preciso lembrar que as inovações podem ser contínuas ou disruptivas. Trabalha-se aqui com o aspecto inovação continua onde incrementalmente o professor constrói mudanças no fazer docente via transformação e adaptação das suas estratégias e práticas em função da observância de resultados experenciados por colegas. Esta é a razão que alicerça a escolha pelas rodas de conversa.

Quanto ao resultado destas interações para construção de inovações contínuas no trabalho dos docentes, Hargreaves (2002, p.115) afirma que "uma inovação bem-sucedida implica mais do que aperfeiçoar habilidades técnicas. Ela também estimula a capacidade de compreensão dos professores em relação às mudanças que estão enfrentando". 
Segundo Modelski, Giraffa e Casartelli (2019) a formação continuada, nesse sentido, pode ser uma alternativa para propor ações de vivências e reflexões sobre práticas desenvolvidas e que estão repercutindo de forma positiva no desencadeamento da aprendizagem dos estudantes. Deste modo, as boas práticas pedagógicas estão pautadas nas construções individuais e coletivas que ocorrem nas relações e articulações que cada docente realiza de forma isolada com seus pares.

$\mathrm{O}$ artigo está dividido em três partes, além da introdução e referências. Na primeira apresenta-se a organização das rodas de conversa e o processo de identificação/seleção dos professores bem como a dinâmica de divulgação, buscando assim o engajamento por parte dos colegas. Na segunda seção detalhamos as rodas, os dados de participação e as percepções dos autores acerca do resultado obtido em cada uma delas. Por fim, apresentase na terceira parte algumas reflexões e lições aprendidas com esta experiência.

\section{RODAS DE CONVERSA COMO ESTRATEGIA DE INTEGRAÇÃO}

Por que rodas e não apenas cursos? "Um indivíduo isolado, muda apenas a si mesmo; trabalhando juntos, muda-se a realidade" (IMBERNÓN, 2012, p.103).

Era preciso uma estratégia que aproximasse os professores do seu cotidiano, permitisse a troca de saberes e a oportunidade de criar espaços de cooperação, assim sendo as rodas se mostram como formato adequado e com oportunidade estratégica. Imbernón (2009, p.9) diz:

[..] para a formação permanente do professorado será fundamental que o método faça parte do conteúdo, ou seja, tão importante o que se pretende ensinar quanto a forma de ensinar.

Acredita-se que a diversificação de ofertas formativas auxilia a criar uma cultura de inovação dentro das mudanças esperadas relacionadas às práticas pedagógicas. A emergência da pandemia foi um catalisador para despertar da necessidade de mudar. Estes movimentos foram registrados em Frankenberg et al. (2020).

A universidade tem tradição em ofertar seminários e processos formativos aos docentes. Dada a especificidade do perfil dos cursos e respectivos docentes, a grande maioria com pouca ou nenhuma formação no que concerne a aspectos pedagógicos, observou-se além de baixa resposta em termos de participação, poucas mudanças em função dos conteúdos e discussões propostas.

A busca por um formato que atendesse as necessidades formativas e fosse engajador levou a ofertar os processos em formato misto: cursos online assíncronos organizados em atividades e com encontros síncronos espaçados de maneira a responder dúvidas e monitorar a aprendizagem dos nossos colegas, palestras com temas que emergem dos atendimentos realizadas pelo NIP (para professores e/ou coordenadores de cursos) e as rodas para integração/ divulgação dos trabalhos fornecidos feitos pelos colegas.

O professor também aprende com os colegas e esse olhar particular às ações construídas pelos seus pares, pressupõe o interesse em manter-se atualizado em relação aos conteúdos e recursos tecnológicos para reorganizar sua aula. Segundo Imbernón (2010, p. 31):

[...] é necessário começar a refletir sobre o que nos mostra a evidência da teoria e da prática formadora dos últimos anos e não nos deixarmos levar pela tradição formadora, para assim tentar mudar e construir uma nova forma de ver o ensino e a formação docente, a fim de transformar a educação e contribuir para uma sociedade mais justa.

No trabalho de Bedini e Del Pino (2018, p.228) relacionado a rodas de conversa, os autores destacam que: 
...esses espaços de formação são aprimorados à medida que ocorrem estudos, discussões, pesquisa e articulação de saberes entre professores, em formação inicial e continuada, acerca do processo de ensinar e aprender química. Neles são oferecidos, ainda, períodos em que os sujeitos têm oportunidades de repensar sua formação pedagógica, aprender sobre metodologias docentes, construir materiais didáticos alternativos, desenvolver microaulas esquematizadas e ambientes de aprendizagens em sequências didáticas, constituindo um processo coletivo de constante açãoreflexão-ação.

Para os autores, as rodas de conversa têm proporcionado um espaço/tempo em que os professores em formação se permitem trocar conhecimentos e aprender a aprender em um momento dialógico de formação coletiva e cooperativa.

Uma vez estabelecido o planejamento das rodas de conversa, iniciou-se uma busca por professores candidatos a conduzir estas rodas, e foram utilizados os registros de atividades realizadas pela PROGRAD nos seminários de formação acadêmica promovidos pela universidade onde diversos colegas ofertaram relatos de práticas e oficinas do tipo "mão na massa" para demonstrarem as diversas maneiras que conduziam suas atividades com seus alunos. E, evidentemente, escolhiam aquelas consideradas como "sucesso" na percepção dos alunos, isto é, receberam por parte discente avaliação positiva no que concerne a colaborar para construção da sua aprendizagem.

Uma vez identificados os professores da escola que participaram destes eventos, foi feito um convite para que os professores idealizadores (ou mesmo praticantes) dessas atividades consideradas diferenciadas pudessem conversar com os colegas.

Tais atividades tiveram início em 2018, onde foi criada uma atividade-piloto a fim de testar o modelo, com relatos curtos (20 a 30 minutos). Este piloto acabou por balizar as estratégias adotadas nas rodas a partir de 2019.

Em 2019, as rodas de conversa foram sistematizadas. Elas foram organizadas com periodicidade semanal, ao longo de três meses, ofertadas em dias da semana alternados e preferencialmente no turno da tarde, pois as aulas se concentravam no turno da manhã e final de tarde e à noite. Logo, buscou-se ofertar as rodas em horários de início ou meio da tarde, variando o dia da semana para gerar uma grade de opções para que os colegas pudessem participar de pelo menos uma ou duas destas oportunidades. Quando em oferta presencial os encontros não foram gravados, fato este que restringiu a disseminação das práticas, porém, permitiu a criação da rede de parcerias que desejávamos. Os professores das rodas passaram a ser uma espécie de referência do assunto abordado. Quando um colega queria uma dica já sabia a quem buscar.

Durante as atividades, observou-se que os participantes estavam bastante interessados e que a troca acontecia além daquele espaço, uma vez que após os eventos, nas salas de professores, por exemplo, era possível notar os colegas conversando sobre o que foi discutido. Acredita-se, desta forma, que mais do que ser um momento formal de discussão sobre temas variados e inovadores, as rodas de conversa promoveram entre os colegas o conhecimento do que cada um vinha desenvolvendo em suas aulas e propiciaram o início de algumas parcerias de trabalho.

\section{RODAS DE CONVERSA REALIZADAS PELO NIP}

Ao longo do segundo semestre de 2019, o NIP da Escola Politécnica organizou treze Rodas de conversa, nas quais os professores ministrantes foram convidados para compartilhar com os demais colegas suas práticas pedagógicas exitosas. Com temas variados, tais como gamificação, cultura maker, objetos de aprendizagem, neuroeducação, pensamento computacional, inteligência artificial, inovação no ambiente escolar, todos os 
encontros foram realizados em um espaço da própria Escola, com participação voluntária dos professores.

A seguir está a relação das Rodas de Conversa de 2019:

- $\quad$ 1a Roda de conversa: Gamificação usando Moodle

- $\quad 2^{a}$ Roda de conversa: Pensamento computacional: do que estamos falando?

- $\quad 3^{a}$ Roda de conversa: Neuroeducação e o ensino de ciências exatas

- $\quad$ 4a Roda de conversa: Objetos de aprendizagem: mitos e fatos

- $\quad$ 5 $\quad$ Roda de conversa: Cultura maker: como aplicar na sua disciplina?

- $\quad$ 6 ${ }^{\text {a }}$ Roda de conversa: Ferramentas de learning analytis no Moodle

- $\quad$ 7ª Roda de conversa: IA e educação: o que se espera nos próximos anos e o que isto nos afeta?

- $\quad$ 8 $\quad$ Roda de conversa: Gamificação usando o Moodle (segunda edição)

- $\quad$ 9a Roda de conversa: Inovação no ambiente escolar

- $\quad 10^{a}$ Roda de conversa: Neuroeducação e o ensino de ciências exatas (segunda edição)

- $\quad 11^{a}$ Roda de conversa: Objetos de aprendizagem: mitos e fatos (segunda edição)

- $\quad 12^{-2}$ Roda de conversa: Ferramentas de Learning Analytics no Moodle

Como se pode perceber pelos títulos das atividades, houve alguns encontros em que foram discutidas as ferramentas do Moodle e as possibilidades de utilização de alguns itens para tornar esta plataforma mais dinâmica. Estes encontros tiveram um caráter um pouco mais prático.

Em outros encontros, os temas foram variados. Foi discutido a necessidade de incentivar o pensamento computacional nos nossos estudantes, para além das disciplinas específicas de informática. Conversou-se sobre o conceito de cultura maker e como ele pode ser aplicado nos processos de ensino e aprendizagem em diferentes áreas do conhecimento, incentivando os alunos a trabalharem de forma colaborativa e com autonomia. Houve também um bate-papo sobre o conceito e características de objetos de aprendizagem e como estes recursos podem ser utilizados com os alunos, assim como as contribuições da neuroeducação para auxiliar no entendimento da aprendizagem.

Um dos temas que chamou mais a atenção dos participantes foi a Inteligência Artificial (IA) e seus impactos na Educação, pois de fato é algo bastante atual e que causa certa inquietação, não apenas em professores, mas em diversos profissionais que podem ter suas atividades afetadas pela IA.

Observa-se, ainda, que algumas rodas tiveram uma segunda edição, uma vez que os encontros eram presenciais e, dependendo dos horários, um grupo de professores interessados não podia participar.

A média de participantes nos treze encontros foi de 18 professores. A Figura 1 apresenta a quantidade de professores participantes em cada Roda de Conversa ocorrida no segundo semestre de 2019.

Com relação ao ano de 2020, já em modelo de ensino remoto, em função do contexto pandêmico da Covid-19, foram organizadas, no segundo semestre, quatro Rodas de conversa, as quais ocorreram na plataforma Zoom. Da mesma forma que no ano anterior, foram convidados os professores que gostariam de compartilhar suas experiências com os colegas. Neste momento, os temas já versavam sobre os desafios e possibilidades do ensino remoto. Além disto todas as rodas foram gravadas e disponibilizados os links de acesso, facilitando a visualização dos temas apresentados, bem como a geração de discussões com os responsáveis sobre cada tema. Em função destes eventos o NIP da 
Escola Politécnica conseguiu informações para a organização de cursos e palestras especificas.

Figura 1 - Professores participantes nas Rodas de conversa em 2019/2

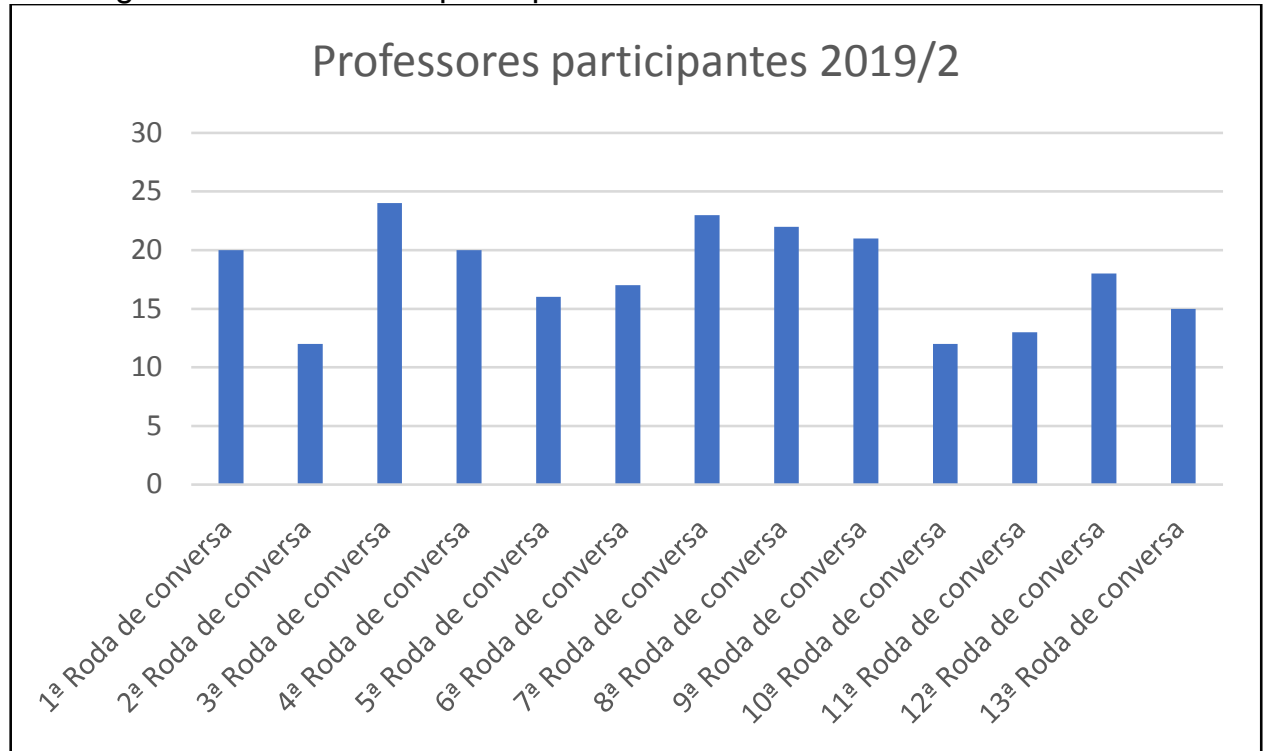

Fonte: os autores (2021)

A seguir a relação das Rodas de conversa de 2020/2:

- $\quad 1$ a Roda de conversa: Sexta-feira tem hora do game

- $\quad$ 2a Roda de conversa: Ensino virtual: o desafio das aulas práticas em tempos de isolamento social

- $\quad 3^{a}$ Roda de conversa: Design Thinking como abordagem norteadora para aprendizagem através de experimentos

- $\quad$ 4⿳亠口冋 Roda de conversa: Relações interpessoais em ambientes virtuais de ensino e aprendizagem: limites e possibilidades.

Em 2020, a média de participantes nos quatro encontros foi de 20 professores. A Figura 2 mostra o gráfico da distribuição do número de professores participantes em cada Roda de Conversa ocorrida no referido ano.

Figura 2 - Professores participantes nas Rodas de conversa em 2020/2

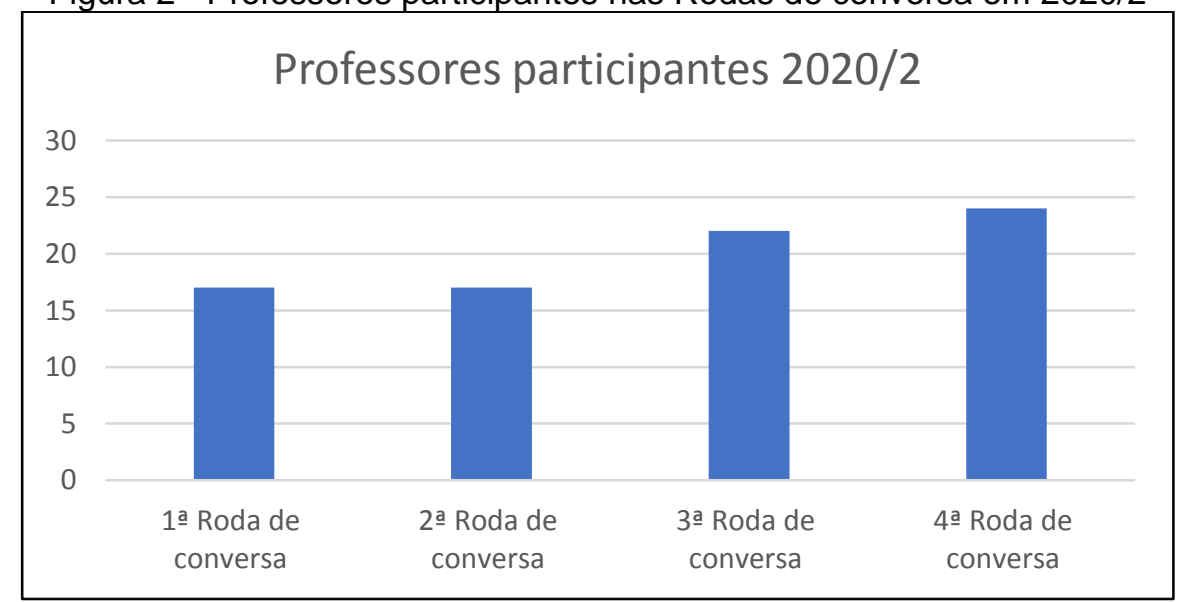

Fonte: os autores (2021) 
Diante dos dados apresentados, tem-se bons indicadores de que ações de capacitação docente, tais como em formato de rodas de conversa, são opções satisfatórias de interação e engajamento de professores na construção de novas possibilidades pedagógicas que objetivam o compartilhamento e a reflexão de experiências e saberes.

Para exemplificar o funcionamento das atividades, as Figuras 3, 4 e 5, mostram alguns dos momentos das Rodas de Conversa que ocorreram em 2019. Pode-se observar que se utilizou um ambiente com possibilidade de interação, ou seja, com a possibilidade de execução do que estava sendo discutido, como em uma oficina de trabalho, fazendo assim com que o professor se tornasse uma parte integrante do processo de discussão.

Figura 3 - Imagens da $1^{\text {a }}$ Roda de conversa: Gamificação usando Moodle

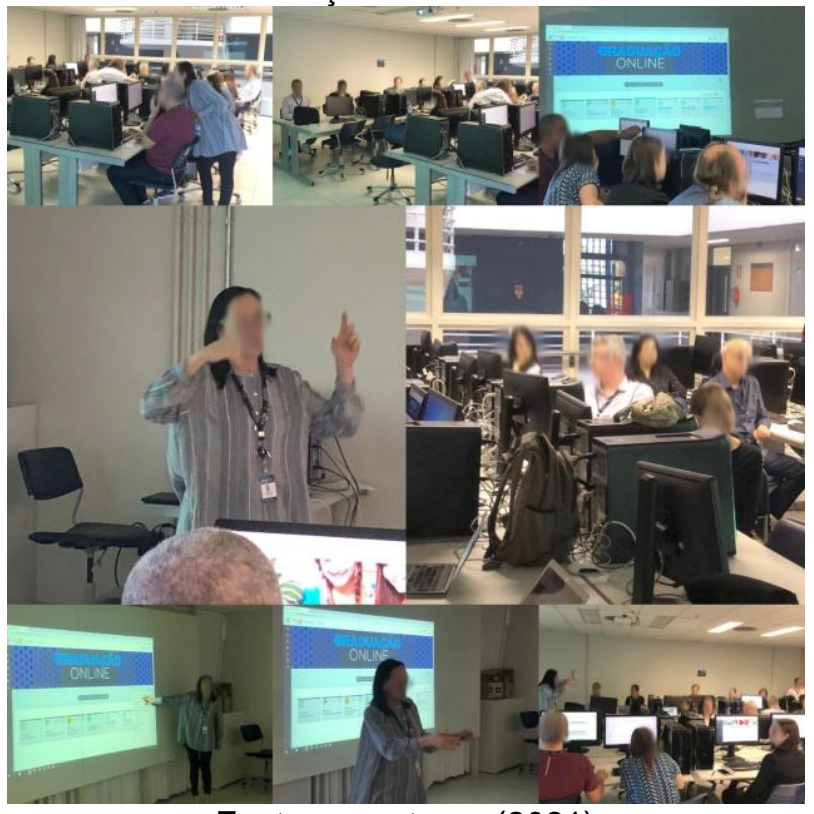

Fonte: os autores (2021)

Figura 4 - Imagens da $3^{\text {a }}$ Roda de conversa: Neuroeducação e o ensino de ciências exatas

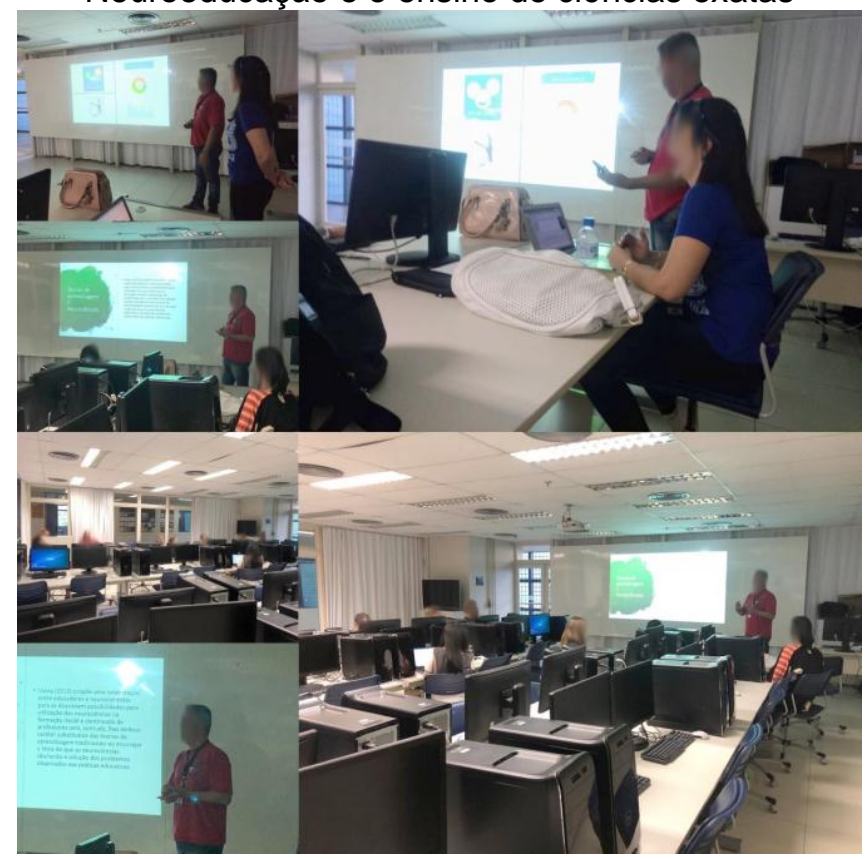

Fonte: os autores (2021) 
Figura 5 - Imagens da 4 ${ }^{\mathrm{a}}$ Roda de conversa: Objetos de aprendizagem: mitos e fatos

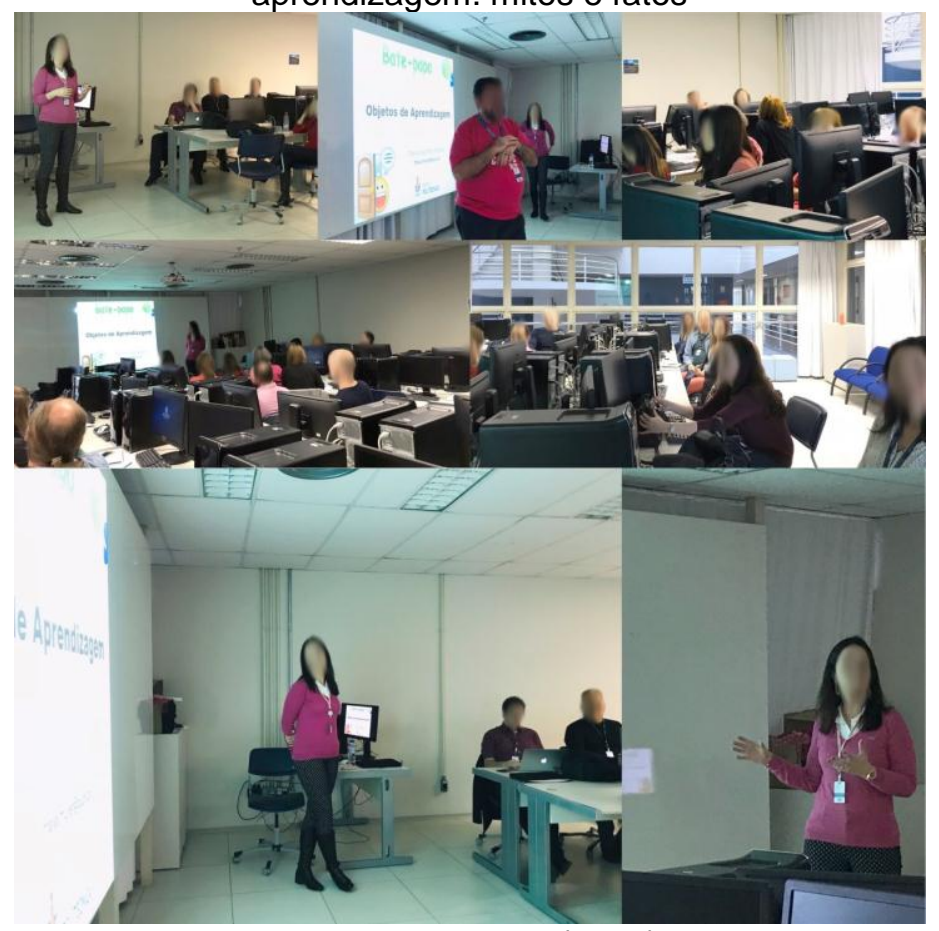

Fonte: os autores (2021)

\section{CONSIDERAÇÕES FINAIS}

Segundo Imbernón (2010, p. 31),

[...] é necessário começar a refletir sobre o que nos mostra a evidência da teoria e da prática formadora dos últimos anos e não nos deixarmos levar pela tradição formadora, para assim tentar mudar e construir uma nova forma de ver o ensino e a formação docente, a fim de transformar a educação e contribuir para uma sociedade mais justa.

A experiência com as rodas de conversa consolidou uma percepção que se tinha acerca da necessidade de os docentes terem oportunidades formativas baseadas em relatos e experiências práticas para que pudessem se inspirar e refletir de forma crítica acerca das suas estratégias, condução e organização das suas aulas e conceber alternativas para diversificar e inovar sua prática pedagógica.

Conforme já mencionado, as rodas são uma das alternativas para se compor o processo de formação continuada em serviço e não se excluem outros formatos, tais como palestras, cursos seminários e workshops.

Acredita-se que é justamente na diversidade de ofertas que se constrói um portfólio de formação que atenda a diferentes perfis e necessidades como no caso da Escola Politécnica que reúne 21 cursos concentrados em 7 grandes áreas, a saber Engenharia, Arquitetura, Computação, Ciências Aeronáuticas, Matemática, Física a e Química.

\section{Agradecimentos}

Agradecemos a todos os professores palestrantes das Rodas de conversa de 2018 por acreditarem na proposta e nos auxiliarem fornecendo ideias para organizar todo o processo que foi sistematizado a seguir e, como não poderia deixar de ser, aos colegas 
que foram "oficineiros" das rodas de conversa de 2019 e 2020 que, generosamente, se dispuseram a apresentar suas práticas pedagógicas, compartilhando experiências, saberes, desafios e possibilidades. Nenhuma ação pode ser implementada sem que os gestores compreendam e, apoiem e viabilizem os recursos necessários e, neste sentido, expressamos nosso agradecimento ao Decanato da Escola Politécnica, pelo apoio e concordância nas atividades pedagógicas organizadas pelo NIP.

\section{REFERÊNCIAS}

BEDINI, Everton; DEL PINO, José Claudio. Interações e intercessões em rodas de conversa: espaços de formação inicial docente Rev. bras. Estud. Pedagógicos. Brasília, v. 99 , n. 251 , p. 222-238, jan./abr. 2018.

FRANKENBERG, C. L. C.; GIRAFFA, L. M.M.; CARNIEL, D. R. Implementação do Núcleo de Inovação Pedagógica na Escola Politécnica da PUCRS In: XLVII Congresso Brasileiro de Educação em Engenharia (COBENGE) e 2 Simpósio Internacional de Educação em Engenharia da ABENGE, 2019, Fortaleza. Anais. Fortaleza. Disponível em: http://www.abenge.org.br/sis_artigo_doi.php?e=COBENGE\&a=19\&c=2327. Acesso em 07 mai. 2021.

FRANKENBERG, C. L. C.; CARNIEL, D. R. GIRAFFA, L.M.M.; MULLER, T. Organizando a emergência posta pela pandemia: um case envolvendo uma Escola Politécnica In: XLVIII Congresso Brasileiro de Educação em Engenharia (COBENGE) e 3 Simpósio Internacional de Educação em Engenharia da ABENGE, 2020, Caxias do Sul. Anais. Caxias do Sul. Disponível em:

http://www.abenge.org.br/sis_artigo_doi.php?e=COBENGE\&a=19\&c=2327. Acesso em 07 mai. 2021.

HARGREAVES, A. Aprendendo a mudar: o ensino para além dos conteúdos e da padronização. Porto Alegre: Artmed, 2002.

IMBERNÓN, Francisco. Formação docente e profissional: formar-se para a mudança e a incerteza. $7^{\text {a }}$ ed. São Paulo: Cortez, 2009.

Formação continuada de professores. Porto Alegre: Artmed, 2010.

Inovar o ensino e a aprendizagem na universidade. São Paulo: Cortez,

2012.

MODELSKI, D.; GIRAFFA, L.; CASARTELLI, A. Tecnologias digitais, formação docente e práticas pedagógicas. Educação e Pesquisa, v.45, p.1 - 17, 2019.

SACRISTÁN, Gimeno J. Poderes instáveis em educação. Porto Alegre: ARTMED Sul, 1999. 


\title{
THE USE OF CONVERSATION CIRCLE AS A STRATEGY FOR THE SHARING OF PEDAGOGICAL PRACTICES IN DIFFERENT COURSES OF POLYTECHNICAL SCHOOL
}

\begin{abstract}
This article presents the training actions organized in the format of conversation circles to create spaces for dialogue that would allow the sharing of pedagogical practices organized/created or adapted by the teachers of the different Polytechnic school courses of a community University, where the students are allocated. Engineering courses. This strategy came to complement the traditional training spaces organized in lectures and online courses offered by the School's Pedagogical Innovation Center (NIP). The experience resulted in creating a network of interests and shares by the teachers, helping to reflect on the need for innovation in pedagogical practice based on the current context of cyberculture. The circles started before the pandemic context and, during these three semesters of remote offers, another space was created that allowed teachers to meet to share discoveries, doubts, anxieties, and create remixed solutions to use in adapted way disciplines.
\end{abstract}

Keywords: Conversation Circle. Remote Emergency Synchronous Teaching. Pedagogical Strategies. Teacher Education. 